\title{
The importance of clinical leadership in the hospital setting
}

\author{
This article was published in the following Dove Press journal: \\ Journal of Healthcare Leadership \\ 2I November 2014 \\ Number of times this article has been viewed
}

\author{
John Daly' \\ Debra Jackson' \\ Judy Mannix ${ }^{2}$ \\ Patricia M Davidson ${ }^{1,3}$ \\ Marie Hutchinson ${ }^{4}$ \\ 'Faculty of Health, University of \\ Technology, Sydney (UTS), Sydney, \\ Australia; ${ }^{2}$ School of Nursing and \\ Midwifery, University of Western \\ Sydney, Sydney, Australia; ${ }^{3}$ School of \\ Nursing, John Hopkins University, \\ Baltimore, MD, USA; ${ }^{4}$ Southern Cross \\ University, Lismore, Australia
}

\begin{abstract}
In many areas of the developed world, contemporary hospital care is confronted by workforce challenges, changing consumer expectations and demands, fiscal constraints, increasing demands for access to care, a mandate to improve patient centered care, and issues concerned with levels of quality and safety of health care. Effective governance is crucial to efforts to maximize effective management of care in the hospital setting. Emerging from this complex literature is the role of leadership in the clinical setting. The importance of effective clinical leadership in ensuring a high quality health care system that consistently provides safe and efficient care has been reiterated in the scholarly literature and in various government reports. Recent inquiries, commissions, and reports have promoted clinician engagement and clinical leadership as critical to achieving and sustaining improvements to care quality and patient safety. In this discursive paper, we discuss clinical leadership in health care, consider published definitions of clinical leadership, synthesize the literature to describe the characteristics, qualities, or attributes required to be an effective clinical leader, consider clinical leadership in relation to hospital care, and discuss the facilitators and barriers to effective clinical leadership in the hospital sector. Despite the widespread recognition of the importance of effective clinical leadership to patient outcomes, there are some quite considerable barriers to participation in clinical leadership. Future strategies should aim to address these barriers so as to enhance the quality of clinical leadership in hospital care.
\end{abstract}

Keywords: management, hospital care, barriers, leadership, clinical leadership, discursive paper

\section{Introduction}

Globally, health care systems in the developed world continue to struggle with escalating demands for services and escalating costs. Service design inefficiencies, including outmoded models of care contribute to unsustainable funding demands. ${ }^{1}$ An example is the continuing practice in many settings to look to hospital emergency departments to provide what are essentially, primary health care services. While some progress and reforms have been achieved, numerous experts point to the need for further system change if services are to be affordable and appropriate in the future. ${ }^{2}$ They note that

[...] further change is still needed, despite years of progress in the quality of health care around the world. This transformation will require leadership - and that leadership must come substantially from doctors and other clinicians, whether or not they play formal management roles. Clinicians not only make frontline decisions that determine the quality and efficiency of care but also have the technical knowledge to help make sound strategic choices about longer-term patterns of service delivery. ${ }^{2}$
Correspondence: John Daly Faculty of Health, University of Technology, Sydney (UTS), PO Box 123, Ultimo, Sydney, NSW 2007, Australia Email john.daly@uts.edu.au 
Effective clinical leadership has been linked to a wide range of functions. It is a requirement of hospital care, including system performance, achievement of health reform objectives, timely care delivery, system integrity and efficiency, and is an integral component of the health care system. ${ }^{2-4}$ Though most people are provided with health care within the community setting, hospital care continues to garner the bulk of funding and attract considerable attention in relation to care quality and related concerns. Indeed, hospitals are very costly and diverse environments that vary in size and complexity, determined in part by their overall role and function within the larger health care system. The services provided by individual hospitals are determined and driven by a number of mechanisms, including government policy, population demographics, and the politics and power of service providers. ${ }^{5}$

However, regardless of the differences, the clinical areas of the hospital are critical to all health care organizations, given that it is at this level where consumers principally engage with the hospital system. It is at this point where consumers are recipients of hospital care and where they witness and experience how the system functions, observing the strengths and inefficiencies of the health care system and conflict and collegiality between and among groups of health professionals. It is also at this point that clinicians, defined as any frontline health care professionals, have opportunities to fulfill leadership roles. For consumers of health care to achieve optimal health outcomes and experience optimal hospital care, many believe effective clinical leadership is essential.

In this paper, we discuss clinical leadership in contemporary health care, definitional issues in clinical leadership, roles of hospitals in contemporary health care, preparation for clinical leadership roles, and the facilitators and barriers to effective clinical leadership in the hospital sector.

\section{Clinical leadership in contemporary health care}

The importance of effective clinical leadership in ensuring a high quality health care system that consistently provides safe and efficient care has been reiterated in the scholarly literature and various government reports. ${ }^{6-8}$ Recent inquiries, commissions, and reports have promoted clinician engagement and clinical leadership as critical to improving quality and safety. ${ }^{9}$ As one Australian example, a key priority nursing recommendation of the Garling Report was that Nurse Unit Manager (NUM) positions be reviewed and significantly redesigned "to enable the NUM to undertake clinical leadership in the supervision of patients [...] to ensure that for at least $70 \%$ of the NUM's time is applied to clinical duties." 8
The remaining time could be spent on administrative and management tasks. In the more recent Francis report ${ }^{7}$ from the UK, a recommendation was made for similarly positioned ward nurse managers to be more involved in clinical leadership in their ward areas. In the United States, clinical leadership has also been identified as a key driver of health service performance, with the Committee on Quality of Healthcare suggesting considerable improvements in quality can only be achieved by actively engaging clinicians and patients in the reform process. ${ }^{10}$

However, leadership in health care is often very complex, and some authors claim it faces unique contextual challenges. For example, Schyve ${ }^{5}$ claims aspects of governance are sui generis in health care, noting

healthcare organizations also have a rather unique characteristic. That is, the chief executive is not the only part of the organization's leadership that is directly accountable to the governing body. In healthcare, because of the unique professional and legal role of licensed independent practitioners within the organization, the organized licensed independent practitioners - in hospitals, the medical staff - are also directly accountable to the governing body for the care provided. So the governing body has the overall responsibility for the quality and safety of care, and has an oversight role in integrating the responsibilities and work of its medical staff, chief executive, and other senior managers into a system that that achieves the goals of safe, high-quality care, financial sustainability, community service, and ethical behaviour. This is also the reason that all three leadership groups - the governing body, chief executive and senior managers, and leaders of medical staff - must collaborate if these goals are to be achieved (Schyve 2009:35). ${ }^{5}$

While nursing is not specifically named in the above quote, we believe nursing to be implicit and integral to leadership in hospitals. There is recognition of the challenges associated with health care governance, evidenced by significant investment internationally in building systems for leadership development in health care. ${ }^{5,11}$ For example, the UK advanced leadership programs have been instituted and run for clinical leaders since 2001 by the National Health System Leadership Centre, ${ }^{12}$ and there are some similar innovations in other countries (see, for example, Ferguson et $\mathrm{al}^{13}$ ). This points to the realization that the cost and consequences of poor clinical leadership greatly outweigh the costs and potential benefits of provision of formal programs to enhance clinical leadership capacity ideally in a multidisciplinary health care team context. ${ }^{12}$ 
Indeed, across the health care sector, evidence exists of the need for clinical leadership to optimize care delivery. In addition to challenges associated with resources and demand, episodes of poor patient outcomes, cultures of poor care, and a range of workplace difficulties have been associated with poor clinical leadership, ${ }^{8,914}$ and these concerns have provided the impetus to examine clinical leadership more closely.

\section{Definitional issues in clinical leadership}

Within the health care system, it has been acknowledged that clinical leadership is not the exclusive domain of any particular professional group. ${ }^{15}$ Rather, all members of the health care team are identified as potential leaders. ${ }^{16}$ Like "leadership," the concept of clinical leadership can be defined in a range of ways; and while a standard definition of clinical leadership providing absolute agreement on meaning is not crucial to progress and is likely to prove difficult, ${ }^{17}$ it is useful to consider the various ways clinical leadership is conceptualized and presented in the literature. While effective clinical leadership has been offered up as a way of ensuring optimal care and overcoming the problems of the clinical workplace, a standard definition of what defines effective clinical leadership remains elusive. ${ }^{15,18}$ Indeed, in some ways it is easier to consider what constitutes poor or ineffective clinical leadership.

A secondary analysis of studies exploring organizational wrongdoing in hospitals highlighted the nature of ineffectual leadership in the clinical environment. The focus of the analysis was on clinical nurse leader responses to nurses raising concerns. Three forms of avoidant leadership were identified:

placating avoidance, where leaders affirmed concerns but abstained from action; equivocal avoidance, where leaders were ambivalent in their response; and hostile avoidance, where the failure of leaders to address concerns escalated hostility towards the complainant. ${ }^{14}$

These forms of leadership failure were all associated with negative organizational outcomes. Similarly, McKee et al employed interviews, surveys, and ethnographic case studies to assess the state of quality practice in the National Health Service (NHS); they report that one of the most important insurances against failures such as those seen in the MidStaffordshire NHS Trust Foundation is active and engaged leaders at all levels in the system. ${ }^{14,19}$

Despite the definitional uncertainty, a number of writers have sought to describe the characteristics, qualities, or attributes required to be an effective clinical leader. Synthesis of the literature suggests clinical leadership may be framed variously - as situational, as skill driven, as value driven, as vision driven, as collective, co-produced, involving exchange relationships, and as boundary spanning (see Table 1). Effective clinical leaders have been characterized as having advocacy skills and the ability to affect change. ${ }^{20,21}$ As well, effective clinical leaders have been linked to facilitating and maintaining healthier workplaces, ${ }^{22,23}$ by driving cultural change among all health professionals in the workplace. ${ }^{24}$ To achieve these positive outcomes, clinical leaders need to be seen as credible - that is, be recognized by colleagues as having clinical competence ${ }^{18,25-27}$ and have the skills and capacity to effectively support and communicate with members of multidisciplinary clinical teams. ${ }^{18,25}$ Taking an individual perspective, effective clinical leaders require personal qualities that reflect positive attitudes toward their own profession, have the courage and capacity to challenge the status quo, effectively address care quality issues, and engage in reflective practice. ${ }^{18,14}$ Pepin et al found that clinical competence, the capacity to lead a team, and being prepared to challenge the status quo were necessary skills for clinical leaders in one Canadian study. ${ }^{28}$ In an Australian study, findings indicated that student nurses want clinical leadership attributes from their clinical preceptors to include being supportive, approachable, and motivating, while being effective communicators. ${ }^{29}$ Table 1 summarizes the characteristics of clinical leadership and the attributes of clinical leaders distilled from the literature.

Despite acknowledging the lack of a standard definition of clinical leadership, the authors in one literature review identified common themes:

[...] the ability to influence peers to act and enable clinical performance; provide peers with support and motivation; play a role in enacting organizational strategic direction; challenge processes; and to possess the ability to drive and implement the vision of delivering safety in healthcare. ${ }^{30}$

Many articles assert that clinical leadership is leadership provided by clinicians often recognized as clinical leaders. Indeed, an important driver of the move toward models of clinical leadership is the notion that clinical leaders "are the custodians of the processes and micro-systems of health care." ${ }^{\prime 11}$ Stanley has contributed a summary of seven clinical leadership characteristics which includes factors such as expertise, direct involvement in patient care, high level interpersonal and motivational skills, commitment to high 
Table I The characteristics of clinical leadership and the attributes of clinical leaders

\begin{tabular}{|c|c|c|}
\hline Leader characteristics & Leader foci & Leader attributes \\
\hline \multirow[t]{3}{*}{ Leadership as situational } & Context specific & Directly involved in care \\
\hline & Diagnose microsystem issues & Custodian of care processes and microsystems \\
\hline & & Reflexivity \\
\hline \multirow[t]{3}{*}{ Leadership as skill driven } & Challenge the process and affect change & Clinical passion and credibility \\
\hline & Innovative problem solving & Expert knowledge \\
\hline & & Courage \\
\hline \multirow[t]{2}{*}{ Leadership as value driven } & Faith and respect & Professional identity \\
\hline & Heightened sense of responsibility & Positive attitudes toward own profession \\
\hline \multirow[t]{4}{*}{ Leadership as vision driven } & Translate broader vision into point-of-care delivery & Strategic view \\
\hline & Interpret managerial agenda for clinicians & Drive \\
\hline & Provide challenging goals & Sees improvement opportunities \\
\hline & & Understands improvement techniques \\
\hline \multirow[t]{4}{*}{ Leadership as collective } & Complementarity & Enabling others to act \\
\hline & Constellation of co-leaders & Advocacy skills \\
\hline & & Approachable \\
\hline & & Works well in team \\
\hline \multirow[t]{4}{*}{ Leadership as co-produced } & All staff have responsibility to lead & Effective communicator \\
\hline & Interdependent & Able to influence others to act \\
\hline & In interaction with others & Inter-personal skills \\
\hline & Networked & Ability to lead a team \\
\hline Leadership as exchange & Modeling the way & Capacity to enlist colleagues \\
\hline \multirow[t]{5}{*}{ relationships } & Inspiring a shared vision & Role model \\
\hline & & Provides support \\
\hline & & Motivator \\
\hline & & Empowers others \\
\hline & & Supports others \\
\hline Leadership as boundary & Spans collegial, bureaucratic, interdisciplinary boundaries & Ability to work across teams \\
\hline spanning & Links across point-of-care microsystems & Systems knowledge \\
\hline
\end{tabular}

Notes: Table distilled from: Clark 20I2;31 De Casterle et al 2008;7 Edmonton 2009;"' McKeon et al 2009; ${ }^{73}$ Stanley $2012 ; 32$ Patrick et al 201 I; ${ }^{34}$ McKee et al 20I3.19

quality practice, and empowerment of others. ${ }^{32}$ In contrast to managerial leadership, which operates through hierarchical superior-subordinate organizational relationships, clinical leadership has a collegiate orientation and a focus upon the patient or service interface. ${ }^{11}$ While some clinical leaders may hold positions of positional authority, primarily the influence of clinical leaders stems from characteristics such as clinical credibility and the capacity for collaboration. While transformational leadership positions the leader as a charismatic shaper of followers, ${ }^{33}$ clinical leadership is more patient centered and emphasizes collective and collaborative behaviors. ${ }^{19,32,34}$

It is apparent that the "theory" of clinical leadership is in an early stage of development, and like leadership in general, in health there is very limited empirical support for specific approaches to enacting effective models. Edmonstone notes following the implementation of numerous clinical leadership programs in the UK the little research undertaken has largely focused on program evaluation, rather than the nature or outcomes of clinical leadership. ${ }^{35}$ As the body of evidence continues to develop, some definitional clarity may be achieved.

\section{Role of hospitals in contemporary health care}

Globally, hospitals are under increased strain and scrutiny. Increased demands and fiscal pressures have increased the pressures on all health professionals as well as clinical and non-clinical staff. Hospitals, once seen as representing "health care," are now recognized as dangerous places, particularly where the most vulnerable, such as children and older people, are exposed to the risk and actual adverse clinical events. A number of nationally and internationally influential reports ${ }^{6-8}$ have resulted in changes in visibility, scrutiny, and accountability in relation to hospital care. This scrutiny has increased the emphasis on the role of health professionals, including nurses, in monitoring standards, developing and evaluating better ways of working as well as advocating for patients and their families; and led to a substantial momentum in the quality and safety agenda, including the promotion of various strategies such as promoting evidence-based practice.

In the hospital sector, the demands placed upon leaders have become more complex, and the need for different forms of leadership is increasingly evident. To derive cost efficiency and improve productivity, there has been intense 
reorganization. Coupled with these reforms has been increasing attention upon improving safety and quality, with programs instituted to move attention beyond singular patient-clinician interpretations of safety toward addressing organizational systems and issues of culture. ${ }^{36}$ Arising from these reforms has been growing recognition that many assumptions of common leadership models are not well suited to delivering change at the point-of-care delivery or to assuring increased clinician and patient engagement in decision making. ${ }^{3}$ Accordingly, there have been calls for a transition to a new phase of hospital leadership, one that places the clinical frontline and clinicians as crucial to leadership within organizations. ${ }^{13,37}$ This transformational shift in the conceptualization of leadership has seen debate move from managerial, senior leader, or singular leader interpretations of leadership to a focus upon clinical leaders and clinical leadership. In part, this shift has been in response to growing recognition that while designated leaders in positions of formal authority within hospitals play a key role in administration and espousing values and mission, such leaders are limited in their capacity to reshape fundamental features of clinical practice or ensure change at the frontline. ${ }^{11}$

There is considerable evidence to suggest nurses may experience dissatisfaction with the working environment in hospitals, ${ }^{38}$ with poor work environments impacting negatively on the delivery of clinical care and patient outcomes. ${ }^{39}$ In seeking to understand this dissatisfaction, work engagement among nurses and other health professionals has been explored from the perspective of burnout and emotional exhaustion ${ }^{40-42}$ with work engagement conceptualized as a positive emotional state in which employees are emotionally connected to the work roles. ${ }^{43}$ While such studies have examined engagement with work from an emotional perspective, engagement can also be understood as a broader concept that includes an employee's relationship with their professional role and the broader organization. ${ }^{44}$ This broader view on employee engagement ties in with the concept of organizational citizenship behavior, which captures discretionary behaviors that are not formally rewarded within the organization that help others, or are displays of organizational loyalty or civic virtue. ${ }^{45}$

The thrust of much recent attention upon attaining reform in hospitals through clinical leadership has positioned clinical leadership as a vehicle for improving clinician engagement in not only their own work, but also the care delivery microsystems in which they operate. This type of work engagement requires forms of citizenship behaviors that are focused upon improving clinical systems and practices. For individual clinicians, broader engagement within the organization with systems and processes requires the capacity for citizenship behaviors that are clinically focused and motivated, both at the level of one's own work and also the broader network of relationships and systems. These forms of "clinical citizenship behaviors" require a fair and just work culture in which individuals can openly identify issues and work together toward solutions. ${ }^{45}$

Importantly, given that clinicians may not necessarily be employees of the hospital in which they work but selfregulated and independent professionals who operate with a level of independence from typical employer-employee relationships, and who may have lower levels of commitment to the institution, understanding clinician engagement beyond the level of engagement with one's own work, toward engagement with the broader clinical quality and safety agenda within the organization has important implications for the success of clinical leadership agendas. ${ }^{46} \mathrm{~A}$ small sample study of head nurses in a large academic hospital ${ }^{47}$ reported the development of clinical leaders improved the quality of the nursing work environment through enhanced communication, increased responsibility and empowerment, improved patientcentered communication, improved clarity and structure, and improved interdisciplinary collaboration.

Hospitals are complex socio-political entities, and the ability for engagement and leadership among clinicians can be hampered by power dynamics, disciplinary boundaries, and competing discourses within the organization. The tension inherent between clinical and administrative discourses is evidenced in the findings from the evaluation of clinical directorate structures in Australian hospitals, with close to two thirds of medical and nursing staff surveyed reporting the primary outcome of such structures was increased organizational politics. ${ }^{48}$ At the same time as there have been growing calls for clinical leadership, there is evidence from Australia that reform and restructure within hospitals has resulted in a loss of nursing management roles and functions. ${ }^{49}$ Despite a policy agenda to foster clinical leadership, there are reports that managerial imperatives can instead primarily focus upon fiscal efficiency or organizational political imperatives, with various factors colluding to silence concerns of clinicians.

Edmonstone ${ }^{11}$ cautions that without structural and cultural change within institutions, the move toward clinical leadership can result in devolution of responsibility to clinicians who are unprepared and under resourced for these roles. Evidence emerging from the NHS suggests particular value in leadership coalitions between managers and clinicians. ${ }^{19}$ Further, strong clinician representation at Board level has been reported to make a difference to clinical engagement. ${ }^{35}$ 


\section{Preparation for clinical leadership roles}

There is also a concern that many health professionals may not be well prepared to understand the nature of leadership, or take on leadership roles because of the lack of content on leadership in undergraduate course curricula. ${ }^{50}$ These deficiencies have been recognized by professional organizations and health service providers, especially in light of wide-ranging inquiries into the quality of health services in a number of countries. ${ }^{6,78}$ As a result, there have been efforts made to overcome these deficiencies in the preparation of health professionals. As Gagliano et al comment, there is some evidence that health service provider groups are attempting to address issues pertaining to leadership issues through design and implementation of leadership development programs. ${ }^{51}$

In the UK, a Medical Leadership Competency Framework (MLCF) has been developed and embraced by professional medical bodies, regulatory authorities, and educational providers. ${ }^{31}$ Similarly, a Clinical Leadership Competency Framework has been developed from the MLCF for use across all regulated nonmedical clinical professions, with the aim to include competencies into undergraduate, postgraduate, and continuing professional education..$^{52}$ Ellis et al note that even with the establishment of these frameworks and an acceptance of them as the "gold standard for developmental activities" 53 for clinical leadership, other programs in the UK in the literature report an apprentice-style program targeting doctors in training and providing them with experiential learning opportunities with senior medical officers. ${ }^{54}$ Also, Leeson and Millar describe a leadership program for allied health professionals and nurses working in community and hospital settings in the UK that aims to build individual leadership capacity. ${ }^{55}$ Such programs running alongside a national approach in some ways epitomizes the complexity of clinical leadership in health care.

Other countries have developed education and professional development programs in clinical leadership for doctors, nurses, and allied health professionals working in their respective health systems. Some of these programs have similar features to UK NHS leadership frameworks and associated strategies. For example, in New Zealand medical schools are working to provide leadership training in their undergraduate medical curriculum. ${ }^{56}$ In Australia, training programs are available to hospital medical registrars in teaching hospitals. ${ }^{57}$ Opportunities for allied health professionals to engage in clinical leadership development programs offer similar opportunities for capacity building in leadership, especially in postgraduate training. ${ }^{58,59}$

Globally, the International Council of Nurses identifies leadership as one of the major considerations underpinning their activities and has established a Global Nursing Leadership Institute as a vehicle for these activities. ${ }^{60}$ In addition to this global approach, local initiatives to enhance clinical leadership have been developed and implemented in a number of countries. Interestingly, while many countries have taken a relatively widespread approach to clinical leadership development, in Australia, New South Wales Health's response to the Garling report has been the "Take the Lead," a program developed specifically for NUMs to enhance their clinical leadership skills through professional development activities. ${ }^{61}$ However, it must be noted that while effective clinical leadership is identified as a key issue to be addressed, and despite a number of strategies designed to enhance clinical leadership, to date there are a lack of studies that show improvements in patient outcomes or outcomes for the health workforce as a result of these strategies. And, as Moscrop comments, "questions persist about what leadership means in medicine". ${ }^{2}$

\section{Facilitators and barriers to achieving effective hospital-based clinical leadership}

Clinical leadership, if it is to be evident and successful, requires broader clinician engagement and forms of citizenship behaviors within the clinical context that mediate the realization of this form of leadership. Much has been written in the organizational and health care literature about employee work engagement and the benefits derived through promoting work engagement. ${ }^{5,19}$ Similarly, organizational citizenship behavior is well rehearsed in the literature. Considerable evidence confirms positive associations between constructs such as job satisfaction, work performance, improved productivity, and engaged employees. ${ }^{5}$ Organizational citizenship behavior has been defined as work-related behaviors that are discretionary, not related to the formal reward systems, and which promote the effective functioning of the organization. The types of behaviors commonly seen to form organizational citizenship behavior include altruism, courtesy, conscientiousness, and civic virtue, ${ }^{63}$ including acts such as helping those with a heavier workload, giving of one's time to help others, not taking long lunch breaks, and completing tasks on time. ${ }^{64}$ The focus of attention on work engagement and citizenship behaviors, both within and outside of the health care literature, has 
largely been upon the general construct of work engagement or disengagement with attention to work roles and tasks. ${ }^{46}$ The turn toward clinical leadership requires attention to different facets of work engagement and citizenship behaviors, in particular the nature of clinical citizenship behavior as opposed to generic forms of these behaviors.

Despite the widespread recognition of the importance of effective clinical leadership to patient outcomes, there are some quite considerable barriers to participation in clinical leadership. Such barriers are noted extensively in the literature and can include lack of incentives, lack of confidence, clinician cynicism, poor communication, poor preparation for leadership roles, curriculum deficiencies at undergraduate level in medicine and health professional courses, experience as participants in poorly constructed clinical leadership programs, inadequate resourcing of development programs, poor leadership, lack of vision and commitment at the higher levels, perceptions of leadership as "other" and not core to a clinical practice role, poor interdisciplinary relationships, role conflict, and at times rejection of the "leader" role as unacceptable impost, resistance to change, and poor team work. . $^{2,250,65-67,69-71}$

Edmonstone $^{35}$ cautions that the emphasis upon competency-based leader development has done little to foster effective clinical leadership in the UK, despite its potential usefulness, and informative and summative evaluation of leader development. Although considerable discussion has occurred on the need for clinical leadership, and large scale pubic inquiries evidence the considerable patient harm that has occurred in the absence of such leadership, ${ }^{7,8}$ there continues to be a major disconnect between clinicians and managers, and clinical and bureaucratic imperatives. The debate over who is best positioned to lead service delivery and the place of clinicians in governance continues.

\section{Conclusion}

Effective clinical leadership is associated with optimal hospital performance. It is allied to a wide range of hospital functions and is an integral component of the health care system. Developing clinical leadership skills among hospital nurses and other health professionals is of critical importance. However, despite the widespread recognition of the importance of effective clinical leadership to patient outcomes, there are some quite considerable barriers to participation in clinical leadership. Future strategies should aim to address these barriers so as to enhance the quality of clinical leadership in hospital care. As the focus on hospital performance intensifies, leadership to increase efficiencies and improve quality will be of increasing importance.

\section{Disclosure}

The authors report no conflicts of interest in this work.

\section{References}

1. Commonwealth of Australia. A healthier future for all Australians - Final report of the National Health and Hospitals Reform Commission. Canberra, ACT: National Health and Hospitals Reform Commission; 2009. Available from: http://www.health.gov.au/internet/nhhrc/publishing.nsf/co ntent/1AFDEAF1FB76A1D8CA257600000B5BE2/\$File/Final_Report_ of_the\%20nhhrc_June_2009.pdf. Accessed March 22, 2014.

2. Mountford J, Webb C. When clinicians lead. McKinsey $Q$ Healthcare. February 1-8, 2009

3. MacPhee M, Chang L, Lee D, Spiri W. Global health care leadership development: trends to consider. J Healthcare Leadersh. 2013;2013:21-29.

4. Siriwardena A. Releasing the potential of health services: translating clinical leadership into healthcare quality improvement. Qual Prim Care. 2006; 14:125-128.

5. Schyve P. Leadership in Healthcare Organizations: A Guide to Joint Commission Leadership Standards. San Diego, CA: The Governance Institute; 2009. Available from: http://www.jointcommission.org/ assets/1/18/wp_leadership_standards.pdf. Accessed April 21, 2014.

6. Department of Health. High Quality Care for All, NHS Next Stage Review Final Report (The Darzi Report). London, UK: Department of Health; 2008. Available from: https://www.gov.uk/government/ uploads/system/uploads/attachment_data/file/228836/7432.pdf. Accessed March 17, 2014.

7. Francis R. Report of the Mid Staffordshire NHS Trust Public InquiryExecutive Summary. London, UK: The Stationary Office; 2013. Available from: http://www.midstaffspublicinquiry.com/sites/default/ files/report/Executive\%20summary.pdf. Accessed March 12, 2014.

8. Garling P. Final Report of the Special Commission of Inquiry: Acute Care in NSW Public Hospitals, 2008 - Overview. Sydney, NSW: NSW Government; 2008., Available from: http://www.dpc.nsw. gov.au/__data/assets/pdf_file/0003/34194/Overview_-_Special_ Commission_Of_Inquiry_Into_Acute_Care_Services_In_New_South_ Wales_Public_Hospitals.pdf. Accessed April 9, 2014.

9. Jowsey T, Yeh L, Wells R, Leeder S. National Health and Hospital Reform Commission and patient-centred suggestions for reform. Aust J Prim Health. 2009;17(2):162-166.

10. Committee on Quality of Healthcare in America. Crossing the quality chasm. A new health system for the 21 st century. Washington, DC: Institute of Medicine; 2001. Available from: http://www.iom.edu/ Reports/2001/Crossing-the-Quality-Chasm-A-New-Health-Systemfor-the-21st-Century.aspx. Accessed February 21, 2014.

11. Edmonstone J. Clinical leadership: the elephant in the room. Int J Health Plann Manage. 2009;24(4):290-305.

12. Edmonstone J. Evaluating clinical leadership: a case study. Leadersh Health Serv. 2009;22(3):210-224.

13. Ferguson L, Calvert J, Davie M, et al. Clinical leadership: using observations of care to focus risk management and quality improvement activities in the clinical setting. Contemp Nurse. 2007;24(2):212-224.

14. Jackson D, Hutchinson M, Peters K, Luck L, Saltman D. Understanding avoidant leadership in health care: findings from a secondary analysis of two qualitative studies. J Nurs Manag. 2013;21(3):572-580.

15. Howieson B, Thaigarajah T. What is clinical leadership? A journalbased meta-review. Int J Clin Leadersh. 2011;17:7-18.

16. Davidson P, Elliott D, Daly J. Clinical leadership in contemporary clinical practice: implications for nursing in Australia. J Nurs Manag. 2006;14(3):180-187.

17. Slavkin H. Leadership for health care in the 21 st century: a personal perspective. J Healthcare Leadersh. 2010;10(2):35-41.

18. Mannix J, Wilkes L, Daly J. Attributes of clinical leadership in contemporary nursing: an integrative review. Contemp Nurse. 2013;45(1): $10-21$. 
19. McKee L, Charles K, Dixon-Woods M, Willars J, Martin G. 'New' and distributed leadership in quality and safety in health care, or 'old' and hierarchical? An interview with strategic stakeholders. J Health Serv Res Pol. 2013;18(2):11-19.

20. Cook MJ, Leathard HL. Learning for clinical leadership. J Nurs Manag. 2004;12(6):436-444.

21. Watson C. Assessing leadership in nurse practitioner candidates. Aust J Adv Nurs. 2008;26(1):67-76.

22. Cummings G, MacGregor T, Davey M, et al. Leadership styles and outcome patterns for the nursing workforce and work environment: a systematic review. Int J Nurs Stud. 2010;47(3):363-385.

23. Fealy G, McNamara M, Casey M, et al. Barriers to clinical leadership development: findings from a national survey. J Clin Nurs. 2011;20: 2023-2032.

24. Jackson D, Daly J. Improving the workplace: the pivotal role of nurse leaders. Contemp Nurse. 2010;36(1-2):82-85.

25. Desveaux L, Nanavaty G, Ryan J, et al. Exploring the concept of leadership from the perspective of physical therapists in Canada. Physiother Can. 2012;64(4):367-375.

26. Jakeman P. Clinical leadership in general practice. Clin Manag. 2004; 12(3):117-122.

27. McNamara M, Fealy G, Casey M, et al. Boundary matters: clinical leadership and the distinctive disciplinary contribution of nursing to multidisciplinary care. J Clin Nurs. 2011;20(23-24):3502-3512.

28. Pepin J, Dubois S, Girard F, Tardif J, Ha L. A cognitive learning model of clinical nursing leadership. Nurse Educ Today. 2011;31: 268-273.

29. Zilembo M, Monterosso L. Nursing students' perceptions of desirable leadership qualities in nurse preceptors: a descriptive survey. Contemp Nurse. 2008;27(2):194-206.

30. Garrubba M, Harris C, Melder A. Clinical leadership: a literature review to investigate concepts, roles and relationships related to clinical leadership. Melbourne, VIC: Centre for Clinical Effectiveness, Southern Health; 2011, Available from: http://www.monashhealth.org/icms_ docs/6079_Clinical_Leadership_A_literature_review_to_investigate_ concepts_roles_and_relationships_related_to_clinical_leadership.pdf. Accessed March 8, 2014.

31. Clark J. Medical leadership and engagement: no longer an optional extra. J Health Organ Manag. 2012;26(4):437-443.

32. Stanley D. Clinical leadership and innovation. J Nurs Educ Pract. 2012;2(2):119-126.

33. Hutchinson M, Jackson D. Hostile clinician behaviours in the nursing work environment and implications for patient care: a mixed-methods systematic review. BMC Nurs. 2013a;12(25):1-12.

34. Patrick A, Laschinger HK, Wong C, Finegan J. Developing and testing a new measure of staff nurse clinical leadership: the clinical leadership survey. J Nurs Manag. 2011;19(1):449-460.

35. Edmonstone JD. Whither the elephant?: the continuing development of clinical leadership in the UK National Health Service. Int $J$ Health Plann Manage. 2014;29(3):280-291.

36. Parand A, Burnett S, Benn J, Iskander S, Pinot A, Vincent C. Medical engagement in organisation-wide safety and quality-improvement programmes: experience in the UK Safer Patients Initiative. Qual Saf Health Care. 2010;19(5):e44.

37. Stanley D, Gannon J, Gabuat J, et al. The clinical nurse leader: a catalyst for improving quality and patient safety. $J$ Nurs Manag. 2008;16:614-622.

38. Hutchinson M, Jackson D. Transformational leadership in nursing: towards a more critical interpretation. Nurs Inq. 2013b;20(1):11-22.

39. Hutchinson M, Jackson D. Troubling fragments and small stories: an analysis of public commentary on nursing through a web blog. Collegian. 2014;21(2):81-88.

40. Bamford M, Wong C, Laschinger $\mathrm{H}$. The influence of authentic leadership and areas of worklife on work engagement of registered nurses. Journal of Nursing Management. 2013;21(3): 529-40.
41. Cho J, Laschinger H, Wong C. Workplace empowerment, work engagement and organizational commitment of new graduate nurses. Nursing Leadership. 19(3):43-60.

42. Laschinger H, Finegan J, Wilk P. New Graduate Burnout: The Impact Of Professional Practice Environment, Workplace Civility, and Empowerment. Nurs Econ. 2009;27(6):377-383.

43. Salanova M, Schaufeli W. A cross-national study of work engagement as a mediator between job resources and proactive behavior. The International Journal of Human Resource Management. 19(1): 116-131.

44. Bakker AB, Albrecht SL, Leiter MP. Key questions regarding work engagement. European Journal of Work and Organizational Psychology. 2010;20(1):4-28.

45. Frankel A, Leonard M, Denham C. Fair and just culture, team behaviours, and leadership engagement: the tool to achieve high reliability. Health Serv Res. 2006;41(4):1690-1709.

46. Bonias D, Leggat SG, Bartram T. Encouraging participation in health system reform: is clinical engagement a useful concept for policy management. Aust Health Rev. 2012;36:378-383.

47. De Casterle BD, Willemse A, Verschueren M, Milisen K. Impact of clinical leadership development on the clinical leader, nursing team and care-giving process: a case study. J Nurs Manag. 2008;16(6): 753-763.

48. Braithwaite J, Westbrook M. Rethinking clinical organisational structures: an attitude survey of doctors, nurses and allied health staff in clinical directorates. J Health Serv Res Policy. 2005;10(1): $10-17$.

49. Kearin M, Johnston J, Leonard J, Duffield C. The impact of hospital structure and restructuring on the nursing workforce. Aust J Adv Nurs. 2007;24(4):42-46.

50. Olsen $\mathrm{S}$, Neale G. Clinical leadership in the provision of hospital care. BMJ. 2005;330(7502):1219-1220.

51. Gagliano NJ, Ferris T, Colton D, Dubitzky A, Hefferman J, Torchiana D. A physician leadership development program at an academic medical center. Qual Manag Health Care. 2010;19(3):231-238.

52. Long P, Lobley K, Spurgeon P, Clark J, Balderson S, Lonetto T. The CLCF: developing leadership capacity and capability in the clinical professions. Int J Clin Leadersh. 2011;17(2):111-118.

53. Bekas S. Evaluating leadership development in postgraduate medical education. Leadersh Health Serv. 2014;27(1):31-40.

54. Ellis B, Rutter P, Greaves F, Noble D, Lemer C. New models of clinical leadership: the Chief Medical Officer Clinical Advisor Scheme. Int $J$ Clin Leadersh. 2011;17:1-6.

55. Leeson D, Millar M. Using the 7 Habits programme to develop effective leadership. Nurs Manag. 2013;20(6):31-37.

56. Gauld R. Clinical governance development: learning from the New Zealand experience. Postgrad Med J. 2014;90:43-47.

57. Rankin D. Clinical leadership: a comparison between New Zealand and Australia. The Quarterly. 2012; February. Available from: http://www. racma.edu.au/index.php?option=com_content\&view=article \&id=461 \&Itemid=142. Accessed March 19, 2014.

58. Fuller P. Program for developing leadership in pharmacy residents. Am J Health Syst Pharm. 2012;69(14):1231-1233.

59. Vong K, Koons K, Carnes P. Implementation of a nontraditional postgraduate year 1 pharmacy residency program. Am J Health Syst Pharm. 2013;70:2019-2028.

60. International Council of Nurses [homepage on the Internet]. About ICN. Geneva: International Council of Nurses (ICN); 2012. Available from: http://www.icn.ch/abouticn.htm. Accessed January 21, 2014.

61. Travaglia J, Debono D, Erez-Rein N, et al. Report on the mid program evaluation of 'take the lead'. Sydney, NSW: University of New South Wales, Centre for Clinical Governance Research - Australian Institute of Health Innovation; 2011. Available from: http://www.health.nsw.gov. au/nursing/projects/Documents/midprogram.pdf. Accessed August 10, 2014. 
62. Moscrop A. Clinical leadership: individual advancement, political authority, and a lack of direction? Br J Gen Pract. 2012;62(598): e384-e385.

63. Moorman R. Relationship between organisational justice and organisational citizenship behaviours: do fairness perceptions influence employee citizenship? J Appl Psychol. 1991;76(6):845-855.

64. Carmeli A, Josman ZE. The relationship among emotional intelligence, task performance, and organizational citizenship behaviors. Hum Perf. 2009;19(4):403-419.

65. Touati N, Roberge D, Denis J-L, Cazale L, Pineault R, Tremblay D. Clinical leaders at the forefront of change in health-care systems: Advantages and issues. Lessons learned from the evaluation of the implementation of an integrated oncological services network. Health Services Management. 2006;19(2):105-122.

66. Tomey A. Nursing leadership and management effects work environments. J Nurs Manag. 2009;17(1):15-25.

67. Martin J, McCormack B, Fitzsimons D, Spirig R. Evaluation of a clinical leadership programme for nurse leaders. J Nurs Manag. 2012;20(1):72-80
68. Greenberg C, Regenbogen S, Studdert D, et al. Patterns of communication breakdowns resulting in injury to surgical patients. Journal of the American College of Surgeons. 2007;204(4):533-540.

69. Chadi N. Medical Leadership: Doctors at the helm of change. McGill Journal of Medicine. 2009;12(1):52-57.

70. Ham C. Doctors in leadership: learning from international experience. Int J Clin Leadersh. 2008;16:11-16.

71. Stanley D. In command of care: clinical nurse leadership explored. J Res Nurs. 2006;11(1):20-39.

72. Edmonstone J. The development of strategic clinical leaders in the National Health Service in Scotland. Leadersh Health Serv. 2011;24(4):337-353.

73. McKeon LM, Norris TL, Webb S, Hix C, Ramsey G, Jacob SR. Teaching clinical nurse leaders how to diagnose the clinical microsystem. J Prof Nurs. 2009;25(6):373-378.
Journal of Healthcare Leadership

\section{Publish your work in this journal}

The Journal of Healthcare Leadership is an international, peer-reviewed, open access journal focusing on leadership for the health profession. The journal is committed to the rapid publication of research focusing on but not limited to: Healthcare policy and law; Theoretical and practical aspects healthcare delivery; Interactions between healthcare and society and evidence-based practices;

\section{Dovepress}

Interdisciplinary decision-making; Philosophical and ethical issues; Hazard management; Research and opinion for health leadership; Leadership assessment. The manuscript management system is completely online and includes a very quick and fair peer-review system. Visit http://www.dovepress.com/ testimonials.php to read real quotes from published authors.

Submit your manuscript here: http://www.dovepress.com/journal-of-healthcare-leadership-journal 